\title{
Coal-Tar-Based Pavement Sealcoat, Polycyclic Aromatic Hydrocarbons (PAHs), and Environmental Health
}

Studies by the U.S. Geological Survey (USGS) have identified coal-tar-based sealcoat-the black, viscous liquid sprayed or painted on asphalt pavement such as parking lots-as a major source of polycyclic aromatic hydrocarbon (PAH) contamination in urban areas for large parts of the Nation. Several PAHs are suspected human carcinogens and are toxic to aquatic life.
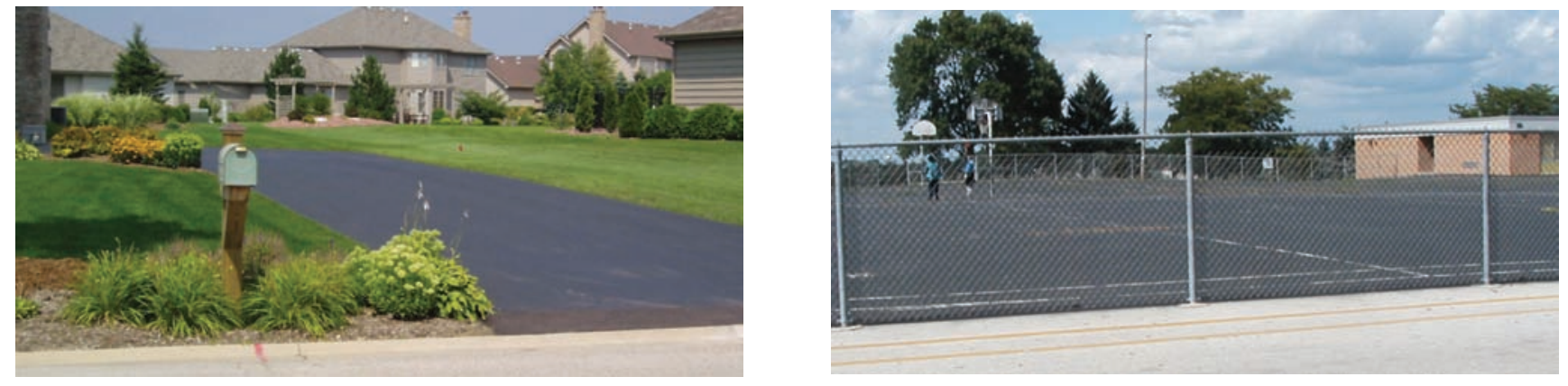

Sealcoat is the black, viscous liquid sprayed or painted on the asphalt pavement of many parking lots, driveways, and playgrounds.

\section{Key Findings}

- Dust from pavement with coal-tar-based sealcoat has greatly elevated PAH concentrations compared to dust from unsealed pavement.

- Coal-tar-based sealcoat is the largest source of PAH contamination to 40 urban lakes studied, accounting for one-half of all PAH inputs.

- Coal-tar-based sealcoat use is the primary cause of upward trends in PAHs, since the 1960s, in urban lake sediment.

- Residences adjacent to parking lots with coal-tar-based sealcoat have PAH concentrations in house dust that are 25 times higher than those in house dust in residences adjacent to parking lots without coal-tarbased sealcoat.

- PAHs move from a sealcoated surface into our environment by many mechanisms: storm runoff, adhesion to tires, wind, foot traffic, and volatilization.

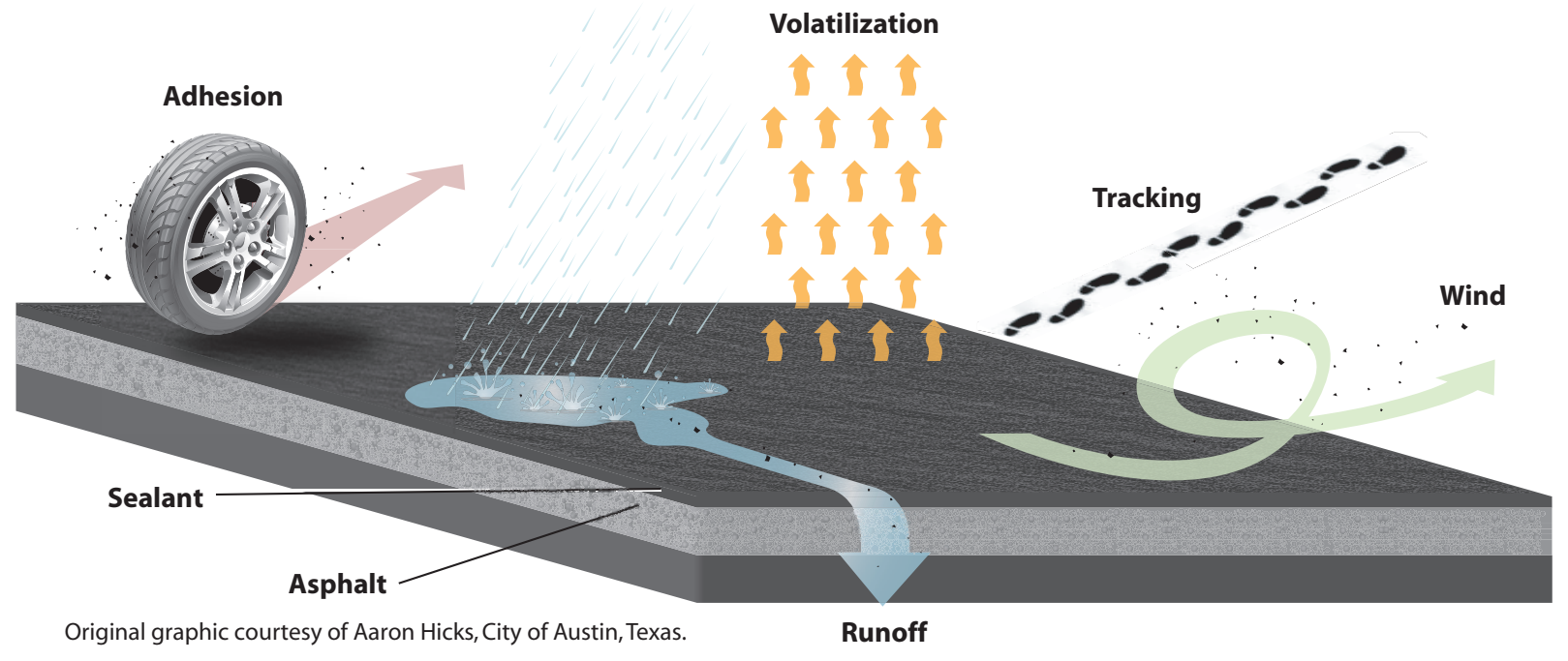




\section{What are Sealcoat, PAHs, and Coal Tar?}

Pavement sealcoat (also called sealant) is a black liquid that is sprayed or painted on some asphalt pavement. It is marketed as protecting and beautifying the underlying pavement, and is used commercially and by homeowners across the Nation. It is applied to parking lots associated with commercial businesses, apartment and condominium complexes, churches, schools, and business parks, to residential driveways, and even to some playgrounds. Most sealcoat products have a coal-tar-pitch or asphalt (oil) base. Coal-tar-based sealcoat is commonly used in the central, southern, and eastern United States, and asphalt-based sealcoat is commonly used in the western United States.

PAHs are a group of chemical compounds that form whenever anything with a carbon base is burned, from wood and gasoline to cigarettes and meat. PAHs also are in objects and materials, such as automobile tires and coal tar, the production of which involves the heating of carbon-based materials. PAHs are of environmental concern because several are toxic, carcinogenic, mutagenic, and/or teratogenic (causing birth defects) to aquatic life, and seven are probable human carcinogens (U.S. Environmental Protection Agency, 2009).

Coal tar is a byproduct of the coking of coal for the steel industry and coal-tar pitch is the residue remaining after the distillation of coal tar. Coal-tar pitch is 50 percent or more PAHs by weight and is known to cause cancer in humans (International Agency for Research on Cancer, 1980). Coaltar-based sealcoat products typically are 20 to 35 percent coal-tar pitch. Product analyses indicate that coal-tar-based sealcoat products contain about 1,000 times more PAHs than sealcoat products with an asphalt base (City of Austin, 2005).

\section{How does Sealcoat get from Driveways and Parking Lots into Streams and Lakes, Homes, and the Air?}

Friction from vehicle tires abrades pavement sealcoat into small particles. These particles are washed off pavement by rain and carried down storm drains and into streams. Other sealcoat particles adhere to vehicle tires and are transported to other surfaces, blown offsite by wind, or tracked indoors on the soles of shoes. Some of the PAHs in sealcoat volatilize (evaporate), which is why sealed parking lots and driveways frequently give off a "mothball" smell. Sealcoat wear is visible in high traffic areas within a few months after application, and sealcoat manufacturers recommend reapplication every 2 to 4 years.
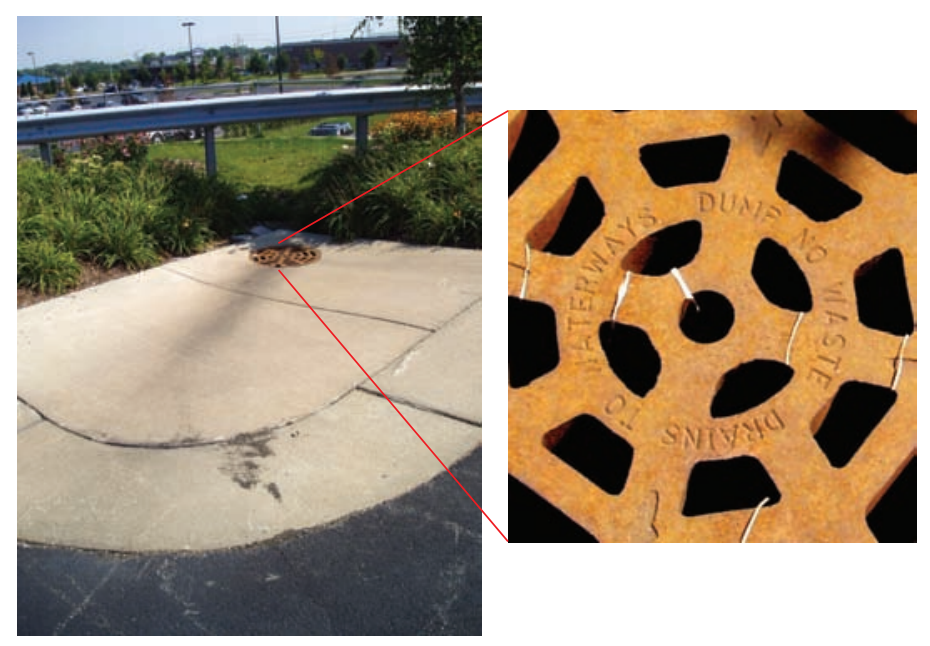

Runoff from sealcoated pavement (black surface) enters storm drains that lead to local streams. Drain grate (inset) is marked "DUMP NO WASTE" and "DRAINS TO WATERWAYS."

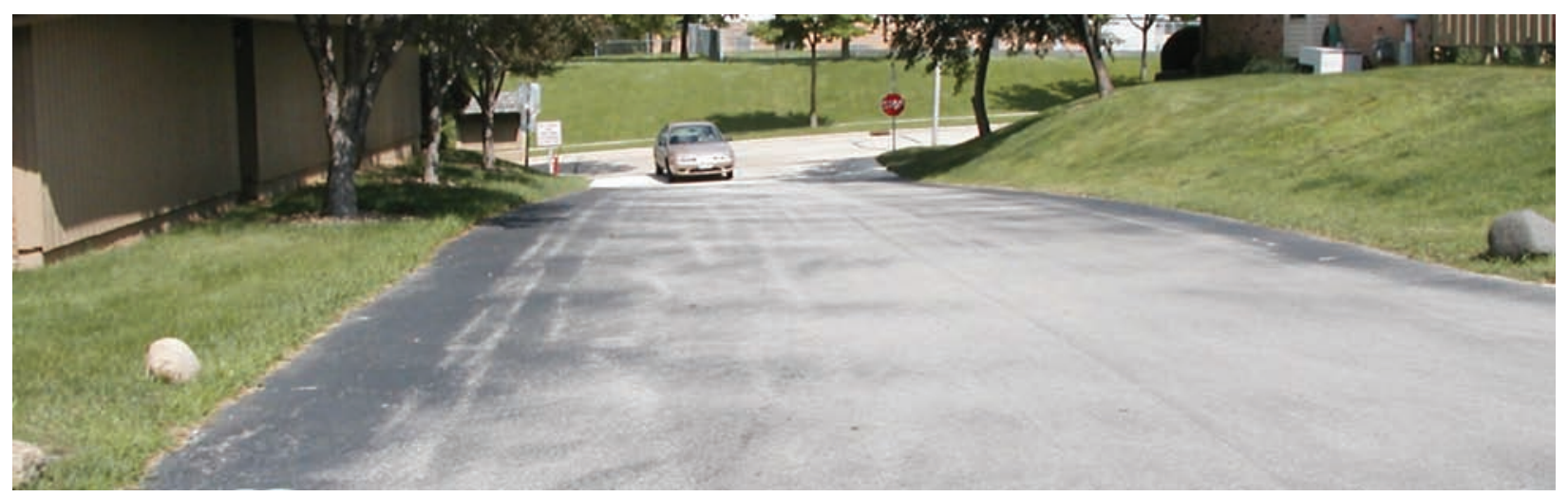

Gray asphalt pavement shows through where sealcoat has worn off the driveway of an apartment complex. 


\section{The East-West Divide}

\section{Regional Product Use Translates to Large Differences in PAH Concentrations}

Does product type really matter? PAH concentrations in the coal-tar-based sealcoat product are about 1,000 times higher than in the asphalt-based product (more than 50,000 milligrams per kilogram [mg/kg] in coal-tar-based products and $50 \mathrm{mg} / \mathrm{kg}$ in asphaltbased products [City of Austin, 2005]). Anecdotal reports, such as Web sites, blogs, and comments by industry representatives, indicate that the coaltar-based product is used predominantly east of the Continental Divide and the asphalt-based product is used predominantly west of the Continental Divide. During 2007-08, the USGS swept dust from sealcoated and unsealcoated parking lots in nine cities across the United States and analyzed the dust for PAHs. For six cities in the central and eastern United States, the median PAH concentration in dust from sealcoated parking lots was $2,200 \mathrm{mg} / \mathrm{kg}$, about 1,000 times higher than in dust from sealcoated parking lots in the western United States, where the median concentration was $2.1 \mathrm{mg} / \mathrm{kg}$. Although both product types are available nationally, these results confirm the regional difference in use patterns (Van Metre and others, 2009).

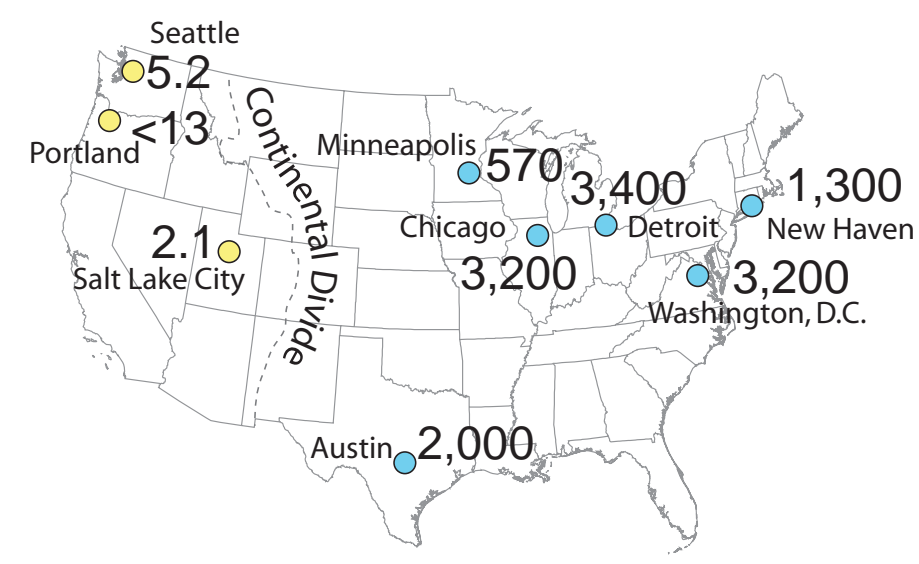

Concentrations of PAHs in dust swept from sealed parking lots in central and eastern U.S. cities, where coal-tar-based-sealcoat use dominates, were about 1,000 times higher than in western U.S. cities, where asphalt-based-sealcoat use dominates. Concentrations shown on the map are the sum of 12 PAHs, in milligrams per kilogram (Van Metre and others, 2009).
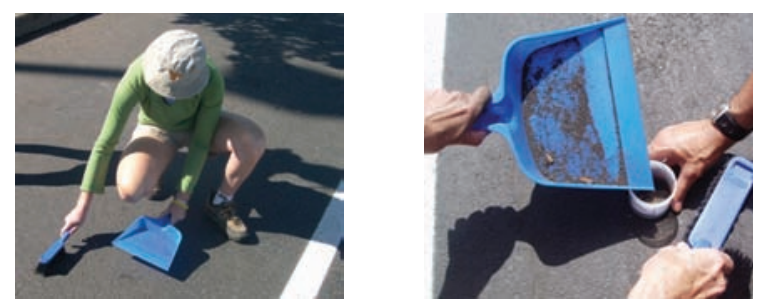

\section{"Fingerprinting" Shows that Coal-Tar Sealant is the Largest Source of PAHs to Urban Lakes}

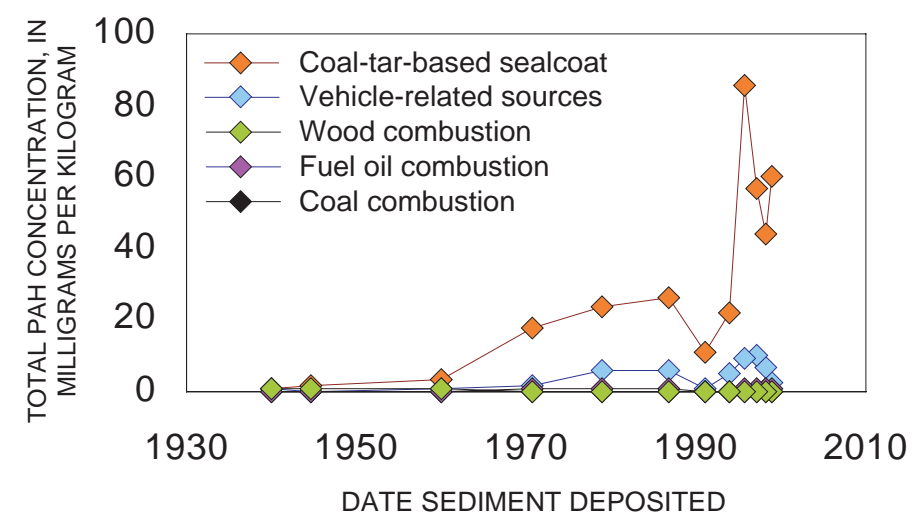

Coal-tar-based sealcoat (orange symbol) is the largest contributor to increasing concentrations of PAHs in Lake Killarney, Orlando, Florida, as determined by chemical fingerprinting. Similar patterns were seen in lakes across the central and eastern United States (Van Metre and Mahler, 2010).
PAHs are increasing in urban lakes across the United States. To better understand why this might be happening, USGS scientists collected sediment cores from 40 lakes in cities from Anchorage, Alaska, to Orlando, Florida, analyzed the cores for PAHs, and determined the contribution of PAHs from many different sources by using a chemical massbalance model. The model is based on differences in the chemical "fingerprint" of PAHs from each source. Coal-tar-based sealcoat accounted for one-half of all PAHs in the lakes, on average, while vehicle-related sources accounted for about one-fourth. Lakes with a large contribution of PAHs from sealcoat tended to have high PAH concentrations; in many cases, at levels that can be harmful to aquatic life. Analysis of historical trends in PAH sources to 8 of the 40 lakes indicates that sealcoat use is the primary cause of increases in PAH concentrations since the 1960s. Identifying where PAHs are coming from is essential for developing environmental management strategies (Van Metre and Mahler, 2010). 


\section{From Outside to Inside \\ Coal-Tar Pavement Sealant Linked to PAHs in House Dust}

House dust is an important source for human exposure to many contaminants, including PAHs. This is particularly true for small children, who spend time on the floor and put their hands and objects into their mouths. In 2008, the USGS measured PAHs in house dust from 23 ground-floor apartments and in dust from the apartment parking lots. Apartments with parking lots with coal-tar-based sealcoat had PAH concentrations in house dust that were 25 times higher, on average, than concentrations in house dust from apartments with parking lots with other surface types (concrete, unsealed asphalt, and asphalt-based sealcoat). PAH concentrations in the dust from the parking lots with coal-tar-based sealcoat were 530 times higher, on average, than concentrations on the parking lots with other surface types.

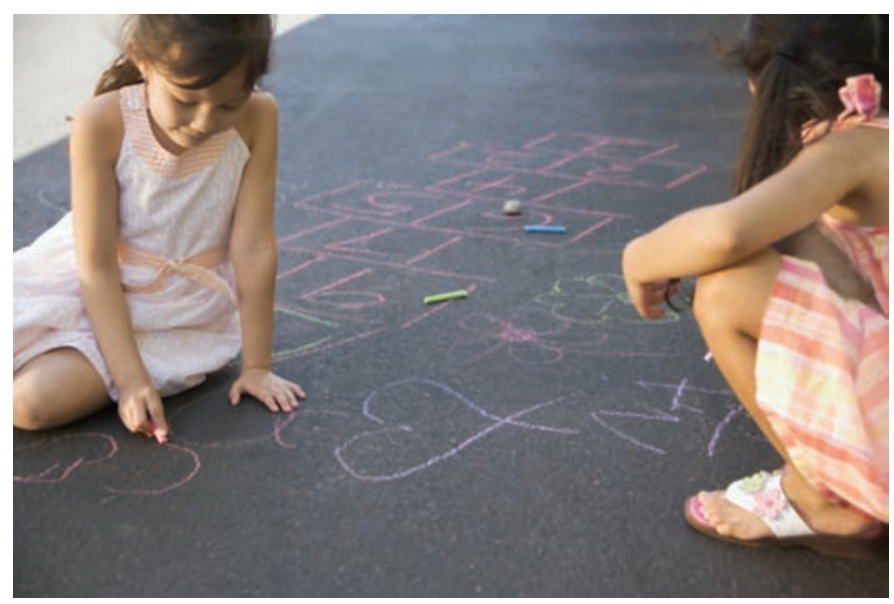

Photograph obtained from Jupiter Images.

What about other sources of PAHs? Although tobacco smoking, candle and incense burning, and barbecue and fireplace use have been suggested to affect PAH concentrations in house dust, this study found no relation between any of these, or the many other factors considered, and PAH concentrations in the house dust. The presence or absence of coal-tarbased sealcoat on the apartment complex parking lot was strongly correlated with PAH concentrations in house dust; the only other variable that was related to PAH concentrations in house dust was urban land-use intensity (the percentage of land near the apartment dedicated to multifamily residential, commercial, office, warehouse, or streets) (Mahler and others, 2010).

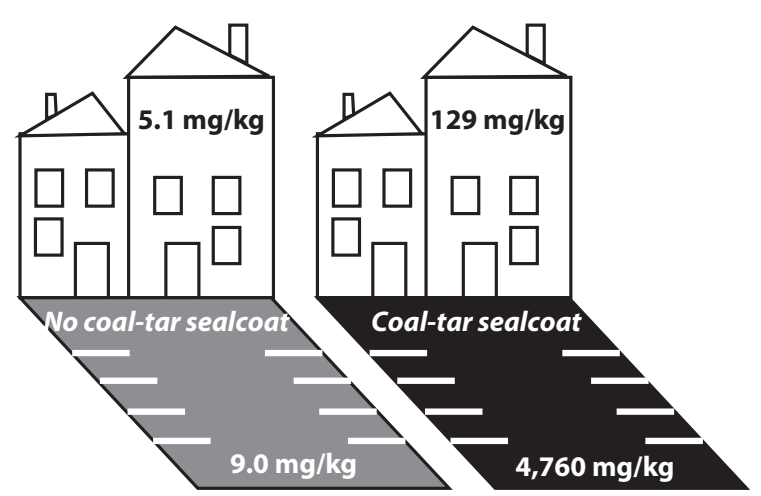

Apartments with coal-tar-based sealcoat on the parking lot had much higher concentrations of PAHs, both in indoor dust and in parking lot dust, than apartments with an unsealed asphalt or concrete parking lot or with a parking lot with asphalt-based sealcoat. Concentrations shown are for the sum of the 16 U.S. Environmental Protection Agency priority pollutant PAHs (Mahler and others, 2010), in milligrams per kilogram (mg/kg).

There are no U.S. health-based guidelines for chronic exposure to PAHs in house dust. The only existing guideline is for a single $\mathrm{PAH}-$ benzo[a]pyrene-issued by the German Federal Environment Agency Indoor Air Hygiene Commission (Hansen and Volland, 1998). The guideline advises minimizing exposure to concentrations of benzo $[a]$ pyrene greater than $10 \mathrm{mg} / \mathrm{kg}$ in dust to avoid adverse health effects. That guideline was exceeded for 4 of the 11 apartments with coal-tar-sealcoated parking lots and for 1 of the 12 apartments with a parking lot with a different surface type. Also of concern is exposure to the sealcoated pavement surfaces themselves through play activities. Dust on some of the sealcoated parking lots had a concentration of benzo $[a]-$ pyrene that was more than 50 times higher than the German guideline.

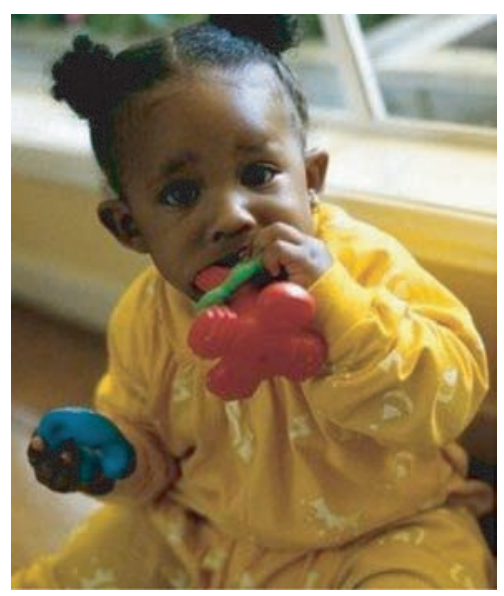

Photograph courtesy of CLEARCorps, Durham, North Carolina. 


\section{Our Environment and Us What are the Concerns?}

Some PAHs are toxic to mammals (including humans), birds, fish, amphibians (such as frogs and salamanders), and plants. The aquatic invertebrates-insects and other small creatures that live in streams and lakes - are particularly susceptible to PAH contamination, especially those that live in the mud where PAHs tend to accumulate. These invertebrates are an important part of the food chain and are often monitored as indicators of stream quality (analogous to the "canary in the coal mine" concept). Possible adverse effects of PAHs on aquatic invertebrates include inhibited reproduction, delayed emergence, sediment avoidance, and mortality. Possible adverse effects on fish include fin erosion, liver abnormalities, cataracts, and immune system impairments. The Probable Effect Concentration (PEC) of $22.8 \mathrm{mg} / \mathrm{kg}$ of total PAHs (MacDonald and others, 2000) — a widely used sediment quality guideline that is the concentration in bed sediment expected to have harmful effects on bottom-dwelling biota-is exceeded in one-third of the central and eastern U.S. urban lakes where PAH sources were studied.

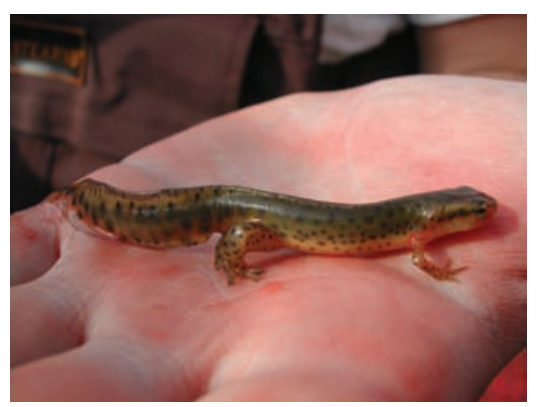

When turned over, red spotted newts that had been exposed to sediment contaminated with coal-tar-based sealcoat had difficulty righting themselves (Bommarito and others, 2010b). Poor reflexes could result in decreased survival. Photograph by Megan Gibbons, BirminghamSouthern College.

Scientific studies have shown a relation between coal-tar-based pavement sealcoat and harmful effects on aquatic life.

- Aquatic communities downstream from stormwater runoff from sealcoated parking lots were impaired (Scoggins and others, 2007).

- Salamanders and newts exposed to sediment contaminated with coal-tar-based sealcoat had stunted growth, difficulty swimming or righting themselves, and liver problems (Bommarito and others, 2010a, b).

- Frogs exposed to sediment contaminated with coal-tar-based sealcoat died, had stunted growth, or developed more slowly than usual (Bryer and others, 2006).

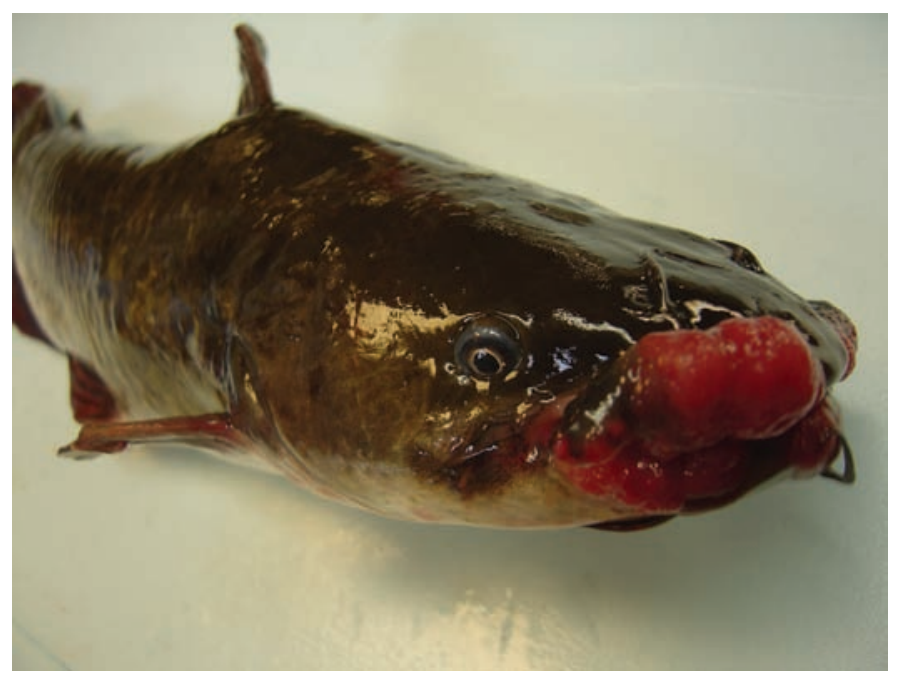

Tumors in brown bullhead catfish from the Anacostia River, Washington, D.C., are believed to be related to elevated PAH concentrations (Pinkney and others, 2009). Photograph by A.E. Pinkney.

Human health risk from environmental contaminants usually is evaluated in terms of exposure pathways. For example, people could potentially be exposed to PAHs in sealcoat through ingestion of abraded particles from driveways, parking lots, or play grounds, or through skin contact with the abraded particles, either directly or by touching toys or other objects that have been in contact with the pavement. Inhalation of wind-blown particles and of fumes that volatilize from sealed parking lots are other possible pathways. PAHs in streams and lakes rarely pose a human health risk from contact recreation or drinking water because of their tendency to attach to sediment rather than to dissolve in water.

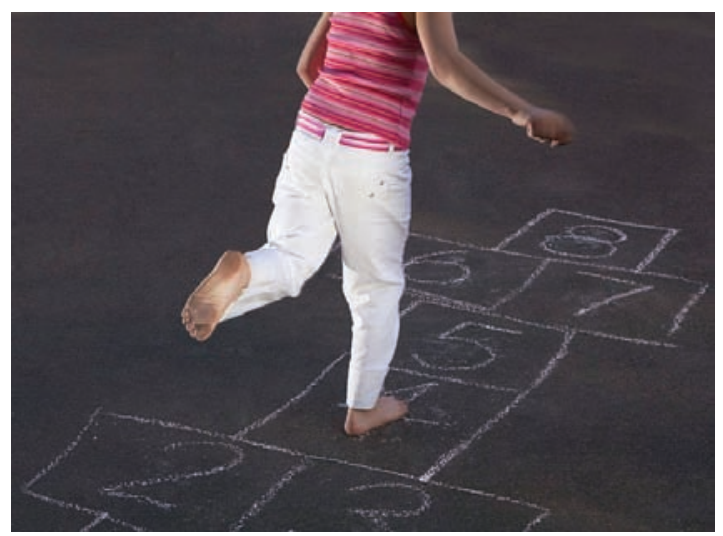

Skin contact is one way humans can be exposed to PAHs. Parking lots and driveways with coal-tar-based sealcoat have concentrations of PAHs hundreds to thousands of times higher than those with asphalt-based sealcoat or no sealcoat. Photograph obtained from Corbis Images, Inc. 
Q) What is coal tar?

A) Coal tar is a thick, black or brown liquid that is a byproduct of the carbonization of coal for the steel industry or the gasification of coal to make coal gas.

Q) What is the difference between crude coal tar, coal-tar pitch, and "refined" coal tar?

A) Coal-tar pitch is the residue that remains after various light oils are distilled from crude coal tar for commercial use. The coal-tar pitch is then separated (refined) into 12 different viscosities, RT-1 (the most fluid) through RT-12 (the most viscous). RT-12 is the viscosity used in coal-tar-based pavement sealcoat.

\section{Q) How can I tell if a product contains coal tar?}

A) To determine if the product has a coal-tar base, look for the Chemical Abstracts Service (CAS) number 65996-93-2 on the product Material Safety Data Sheet (MSDS). The words "coal tar," "refined coal tar," "refined tar," "refined coal-tar pitch," or other similar terms may be listed on the MSDS or on the product container.

\section{Q) Is sealcoat used on roads?}

A) Use on roads is extremely rare. Occasionally a private property, such as a housing development, will choose to have the roads sealcoated.

\section{Q) Is use of coal-tar-based sealant regulated?}

A) Several jurisdictions, including the City of Austin, Texas, the City of Washington, D.C., Dane County, Wisconsin, and several suburbs of Minneapolis, Minnesota, have banned use of coal-tar-based sealcoat. Similar bans are under consideration in other jurisdictions.

For more information on USGS research on PAHs and coal-tar-based sealcoat go to http://tx.usgs.gov/coring/ allthingssealcoat.html.

Publishing support provided by Lafayette Publishing Service Center
Bommarito, T., Sparling, D.W., and Halbrook, R.S., 2010a, Toxicity of coal-tar pavement sealants and ultraviolet radiation to Ambystoma Maculatum: Ecotoxicology, v. 19, no. 6, p. 1,147-1,156.

Bommarito, T., Sparling, D.W., and Halbrook, R.S., 2010b, Toxicity of coal-tar and asphalt sealants to eastern newts, Notophthalmus viridescens: Chemosphere, v. 81, no. 2, p. 187-193.

Bryer, P.J., Elliott, J.N., and Willingham, E.J., 2006, The effects of coal tar based pavement sealer on amphibian development and metamorphosis: Ecotoxicology, v. 15, no. 3, p. 241-247.

City of Austin, 2005, PAHs in Austin, Texas, sediments and coal-tar based pavement sealants: Watershed Protection Department, 55 p., accessed September 14, 2010, at http://www.ci.austin.tx.us/watershed/downloads/coaltar_ draft_pah_study.pdf.

Hansen, D., and Volland, G., 1998, Study about the contamination of PAH in rooms with tar parquetry adhesive: Otto-GrafJournal, v. 9, p. 48-60.

International Agency for Research on Cancer, 1980, Coal tars and coal tar pitches: accessed September 14, 2010, at http:// ntp.niehs.nih.gov/ntp/roc/eleventh/profiles/s048coal.pdf.

MacDonald, D.D., Ingersoll, C.G., and Berger, T.A., 2000, Development and evaluation of consensus-based sediment quality guidelines for freshwater ecosystems: Archives of Environmental Contamination and Toxicology, v. 39, p. 20-31.

Mahler, B.J., Van Metre, P.C., Wilson, J.T., Musgrove, M., Burbank, T.L., Ennis, T.E., and Bashara, T.J., 2010, Coal-tarbased parking lot sealcoat-An unrecognized source of PAH to settled house dust: Environmental Science and Technology, v. 44, p. 894-900.

Pinkney, A.E., Harshbarger, J.C., and Rutter, M.A., 2009, Tumors in brown bullheads in the Chesapeake Bay watershed-Analysis of survey data from 1992 through 2006: Journal of Aquatic Animal Health, v. 21, p. 71-81.

Scoggins, M., McClintock, N., Gosselink, L., and Bryer, P., 2007, Occurrence of polycyclic aromatic hydrocarbons below coal-tar-sealed parking lots and effects on stream benthic macroinvertebrate communities: Journal of the North American Benthological Society, v. 26, no. 4, p. 694-707.

U.S. Environmental Protection Agency, 2009, Integrated Risk Information System (IRIS): accessed September 14, 2010, at http://cfpub.epa.gov/ncea/iris/index.cfm.

Van Metre, P.C., and Mahler, B.J., 2010, Contribution of PAHs from coal-tar pavement sealcoat and other sources to 40 U.S. lakes: Science of the Total Environment, v. 409, p. 334-344.

Van Metre, P.C., Mahler, B.J., and Wilson, J.T., 2009, PAHs underfoot-Contaminated dust from coal-tar sealcoated pavement is widespread in the United States: Environmental Science and Technology, v. 43, no. 1, p. 20-25.

Any use of trade, product, or firm names is for descriptive purposes only and does not imply endorsement by the U.S. Government. 